\title{
Linguistic Deviation in Pakistani Print Media Advertisements
}

\author{
* Abdul Hamid, Lecturer (Corresponding Author) \\ ** Dr. Akbar Ali, Assistant Professor \\ **** Dr. Fazal Hanan, Assistant Professor
}

\begin{abstract}
Linguistic strategies have been widely utilized to function as a tool for persuasion. The present study aims to investigate linguistic deviation in advertisements in Pakistani print media. There are different manifestations of linguistic deviation such as morphological, orthographic, semantic, and syntactic. Data were collected from different national and international advertisements. The data were analyzed using the contents analysis technique of data analysis. In the analysis of linguistic data taken from advertisements, the linguistic deviations have been highlighted and their functions have been identified. The result of the study says that seven types of linguistics deviation have been employed by advertisers in Pakistani print and electronic media and the purpose of deviation is to attract the attention of the readers/viewers (customers).
\end{abstract}

Keywords: Linguistic Deviation, Media, Newspaper, Morphological Deviation, Semantic Deviation Syntactic Deviation

\section{Introduction}

\section{Language and Advertising}

Advertising technique always appears to be appealing and memorable. Advertisers use selective words and phrases for advertising. Advertising is an inescapable aspect of the advanced entrepreneur customer society whose extraordinary feature is its competitive fight. The word 'advertisement' means "drawing attention to something", or informing or enlightening someone or something. The main thrust to allure the public in the advertisement is its deviations having a strong impact on the minds of consumers. Advertising is a type of influence that is directed at large numbers of people. Advertising has become a fundamental part of our life. It seems we exist in the advertising world domain. The marketing vocabulary is worthwhile since it involves diversities or more accurately variations. Advertisers directly utilize deviations to attract consumers. The language of advertising is against the norms and conventions of a standard language, but even then, the inclination is given to this language because of its varieties. Such varieties entice customers and a clear route for product sale. So, the key emphasis here is to explore linguistic dissimilarity found in structures of advertisements (Weijters, Puntoni, \& Baumgartner, 2017).

According to the free encyclopedia Wikipedia, Advertising is the promotion of things such as goods, services, companies, and ideas performed by a branded sponsor. The business community views advertisement as a part of a strategy to promote sales.

The American Heritage Dictionary defines Advertisement as:

'The activity of attracting public attention to a product or business, as by paid announcements in the print, broadcast, or electronic media.'

According to Investor words glossary:

"Description or presentation of a product, idea, or organization, to induce individuals to buy, support, or approve of it."

An authentic investigation of all previously mentioned definitions uncovers a consistent finding that advertisement gives a strong and viable stage for the up degree of products, ideology, and anything associated with the uplifting of goods. The prime target in this association is to infuse powerful intrigue into the minds of consumers to purchase the items. This paper investigates linguistic deviation as a strategy to attract customers. There exists an extensive literature on the nature of the

\footnotetext{
* University of Swat Email: abdulhamid@ uswat.edu.pk

** University of FATA Email: akbar.iub@gmail.com

*** University of FATA Email: dr.hanan@fu.edu.pk
} 
language of media. This study, however, specifically targets the linguistic deviation in Pakistani print; unique strategies for marketization of commodities.

\section{Advertisers and Marketers use Language Diversities}

Semantic, lexical, phonological, morphological, and syntactic deviations and so forth are intentionally utilized by business people in their advertising language to persuade purchasers successfully. The term 'deviation' indicates an unconventional manifestation of words that are in opposition to standard and established norms mutually on the agreement in societal setup. Such deviation against standards may embrace numerous structures, for example, grammatical, lexical, syntactic, and morphological. The field of advertising takes its starting point from the advertere', a word derived from Latin, implies; 'a mean used to grab the attention of common people toward something which drives them to some particular way and destination. According to Donnell and Todd (1980), the realm of advertisement is a complex notion because it involves two interacting processes called communication and persuasion. Both of the processes are in turn many-faceted. Consequently, advertisers regularly use language in manners that depart from convention. They produce stretches of language which can't be clarified by an English grammar while being interpretable (Widdowson, 1972). Chi and Hao (2013) claims that deviation in advertising can attract the audience's attention to go through the advertisement and even persuade them to buy the products advertised. Since advertising got mainstream, analysis on the ad text, script or content has additionally risen in huge numbers. Various studies have been completed and numerous phonetic wonders in advertisements including deviation have been found and considered. My focus is to find potential diversities employed by advertisers in the text or script of the language of advertising on print media. We expect that we can bring this unpredictable phenomenon back into a linguistic field in the advertisement context. My article further investigates that deviations effectively utilized can genuinely assist advertisers with applying the deviation methodology productively and effectively. Variation is a distinguishing feature of human language. There is always more than one way of saying something. Speakers may have varied pronunciation (accent), word choice, and morphology, and syntax. Language variety is a central idea in sociolinguistics.

\section{Linguistic Deviations and Foregrounding}

The author uses different, unique, and unconventional language to make his writing creative, innovative, and effective. He can give a surprise that will have a profound effect on the minds of his/her readers. This sort of utilization of language is known as linguistic deviation. There is a deviation from the standard norms of literary convention or language in use. Leech (2014) gives a concept of foregrounding with linguistic deviation. He claims that if someone is desirous of researching to know the magnitude of a masterpiece must pay attention to the component of interest and surprise, rather than focusing on the programmed design. Such a deviation from the linguistic social norms is called foregrounding. Linguistic deviation is the foregrounding while the language is backgrounding.

\section{Literature Review}

Leech and Short (1981) argue that style is how language has been utilized by certain persons in a given context to achieve certain objectives. Stylistics deals with the way language is used specifically in literary works or in a text in general. Similarly, this subject also investigates stylistic features in a specific literary text by associating the features of the text with a particular writer.

This type of analysis aims to show the creative aspect of a language. It also helps incomprehension of a literary text or a text in general. The analysis of style can be done in two different ways. In the first one what is said (theme) is separated from how it is said (form). In the second one how the message or meaning is communicated while utilizing different means is focused. Linguistic knowledge can be used to describe stylistic features found in a text. These linguistic features can be phonological, morphological, syntactic, and semantic features. In this paper, the focus is on the linguistic deviation as a tool for persuasion in Pakistani print media advertisements

Leech and Short (1969), (1981) (2007) analyze style regarding the concept of foregrounding. Foregrounding in poetry or prose is based on deviation from linguistic norms, which may surface in an unexpected irregularity. They have distinguished three levels of deviation:

Primary deviation: Primary deviation is the type of deviation in which the language deviates from the general linguistic norms. 
Secondary deviation: Secondary deviation is the type of deviation wherein the language deviates from norms of conventional poetic regularity, as in metrical variation and run-on lines in verse.

Tertiary deviation: In Tertiary deviation, the language deviates from the norms established within a literary text.

Charles (2001) asserts about advertising that the language of advertisements deviates from the linguistic conventions however, all linguistic conventions are not abandoned altogether. Djafrova (2008) analyzed the pun and its usage in the structure of advertisements. The complex nature of pun is unveiled through pragmatic and qualitative analysis. Pun can be interpreted into many layers of meanings due to its ambiguous nature. Djafrova points out that pun has two dimensional meanings due to its paradoxical feature.

According to Kagira (2009, advertisers pay attention to the morpho-syntactic, semantic and phonological aspects of the language of advertisement. Ezejideaku (2010) analyzed advertisements of African language. He observed many linguistic devices in his study of the African language of advertisements, mainly at semantic, syntactic, phonological, and morphological linguistic devices. This proves that the African language of advertisements pays more focus on the aesthetic pleasure of consumers than the purpose of trade. Ugwa another prominent sociolinguist conducted experiments on advertisements of African language. Like Ezejideaku, he navigated his analysis at a semanticbased level in 2010.

According to Emodi (2011) language of advertising is highly innovative, productive, and alluring. He further exposes that to keep the long-lasting influence of advertisements, advertisers work hard to manipulate language convincingly and emphatically. The novelty and freshness of the language of advertisement attracts the attention of the people, wins their trust, and change their mindset. Therefore, for the said purpose the deviation is justified (P.10).

Akinbode (2012) maintains that language plays a strong role on account of its versatile, undiminished, and influential nature. Additional linguistic elements like 'situation in a context' and 'illustration' play a significant role to formulate and design the overall texture of advertisements. He has explored all related linguistic components which pave the way for the persuasion of people of any community to subsequent purchase of products. The matter investigated in this paper is not investigated in the Pakistani context.

\section{Methodology}

This paper exclusively deals with the linguistic deviation in the advertisement in Pakistani print media. Only print media was selected because access to data was easier as compared to others. The persuasion strategies adopted in media are different and distinct. All examples in this paper are Pakistani newspapers: Akhbar e Jahan, Dawn, and The News. The ads were published from August 2018 to December 2018. Advertisement samples were randomly collected from the above-given newspapers. The collected ads were analyzed in terms of linguistic deviation. Ads were collected from the selected newspapers. Then those ads were identified where there was linguistic deviation.

\section{Results and Discussion}

Out of eight linguistic deviations mentioned by Geoffrey Leech, the following three linguistic deviations are found in Pakistani print media.

\section{Morphological Deviation \\ Neologism}

Neologism means the creation of new words. Neologism by advertisers is a typical kind of morphological deviation. Such type of derivation makes the word unique thereby making it attractive for the readers. It is a continuous process to meet the challenges of advertising in the modern era. This morphological deviation is used in frequent practice by modern copywriters because it yields more power of attraction and persuasion on part of common folks. According to leech (1969) neologism is not only a 'violation of lexical rule', rather it is an existing rule applied with greater generality by relaxing the otherwise usual restriction on its operation. New morphemes are created to meet the demand of the market in the advertising sector. Such type of compounds are found in general use.

One of the typical morphological deviations is coinage. New morphemes, words, and idioms are coined from time to time. This technique of creativity in language has been found active in the field of advertising because the coined words are attractive. At the same time, coinage bridges the gap between products and customers. The newly coined words generally attract the attention of the readers. For example; 
(1) "The Orangemostest Drink in the world." (Orange juice)

The word of "orangemostest", by adding "most" and "est" as dual suffix after "orange", refreshes the mind of the readers. At the same time, the emphasis on the superlative adds the meaning of extra quality by mark it the best for the customers.

(2) "Give a Timex to all, to all a good time." (Timex watch)

-ex suffix attached to the word 'time' adds the meaning of excellence to the name. -ex in Timex (watch) indicates excellence in timekeeping. Most of the advertisers use suffix -ex for excellence. Such types of suffixes are found across the board in the advertising market.

(3) "We know eggsactly how to tell eggs."(Egg ad)

In the given example the word 'exactly' has been modified so that to give a humorous impression. The coined word 'eggsactly' has been used instead of 'exactly'. Thus the word has been made more catching for readers. Similarly in the following ads, BIRD has been presented in a rather unconventional way.

(4) The BERD (The Bank of European Reconstruction and Development) in hand is worth than two in the bush.

The idiom looks confused on first hand. However, when the reader notices that BIRD is an acronym of The Bank of European Reconstruction and Development bird the ads start giving a unique impression. In this way, the advertisers present things out of the way thereby making it such that it stays longer in the mind of the readers.

The morphology of words has been transformed by advertisers in such a way, it gives a unique impression consequently attracting the attention of the readers. There are different manifestations of morphological deviation in advertisements. The following illustrate some of them:

\section{Blending}

When two words are combined to make a new word such a process is called blending. Advertising has been found utilizing this process for creating new words for advertisement. For instance, the word 'canolive' oil is a blend of two words 'canola' and 'olive', yielding. This type of word, on one hand, indicates the source from which the oil is extracted while on the other hand, this indication of the source makes the brand very attractive for the customers.

\section{Word Coinage}

Word coinage is also very common in Pakistan print media. Advertisers introduce new words and exploit them for advertisement purposes. In coinage formulation, the base of a conventional word is coined with prefixes or suffixes to reshape it into a new form. 'Cheetos' is one of the examples of word coinage in advertisement. This word is a combination of 'cheeta and os'.

\section{Orthographic Modification}

The data in a table. 1 shows that like other deviations, advertisers most of the time deviate from the standardized orthographic form of a word to make it unique thereby make it attractive. Several examples are there wherein the orthographic form of the advertisement word significantly deviates from the standard form of the word. In the following different brands, names are given which deviates from the standard.

Table. 1

\begin{tabular}{ll}
\hline Standard spelling & The deviated form \\
\hline Super & Sooper (biscuits) \\
Juice & mangoes joos \\
phone & Ufone \\
Can baby & Canbebe \\
\hline
\end{tabular}

This deviation might enhance the views of the product advertisement. The advertisers use these strategies to enhance the marketing of the product.

\section{Foreign Words}

These words are borrowed from many other languages to impart a quality of products more effectively. Words imported from other languages endorse features of products and drag consumers into buying products under the pretext of endorsement. In our Pakistani print media utilization of foreign words is a common practice. The use of English language words with Urdu language is a common practice in this connection. For example, if we look into the aviation industry of Pakistan like Pakistan Aeronautical Complex (PAC), it promotes its production by showing endorsement of China aeronautical Corporation (CATIC), Turkish aeronautical industry (TAI) and Lockheed \& 
Martin aerospace firm of USA. Such endorsements in collaboration with foreign words act as brand ambassadors for PAC to actualize international contracts between different delegations of world countries for the sale of training and fighter aircraft.

\section{Formation of New Words and Phrases}

The formation of new words and phrases is a very productive process in linguistic development. In the field of advertisement, the same process is equally found fruitful and frequently employed. The language of advertising has introduced many new words to our vocabulary.

Compounding, affixation, blending, shortening (contains clipping, acronyms, and initialisms), etc are tools used by copywriters to introduce new words and phrases in the body of the advertisement. Some examples are: canolive, fone, dostea, brite etc.

\section{Representation of Morphological Deviation in Print Media of Pakistan}

Table. 2

\begin{tabular}{ll}
\hline Brand names & Morphological process \\
Meandmyheels & Orthographic + Blending \\
Sooper & Orthographic \& Clipping \\
BBQ & Acronym \\
Im Lovin It & Orthographic \\
Canbebe & Blending + Orthographic \\
Fuelink & Blending \\
Ufone & Coinage, Ortho \& Blending \\
Canolive Oil & Blending \\
\hline
\end{tabular}

\section{Semantic-Based Deviation}

Semantic-based deviation in the language of advertising purposefully and knowingly departs one certain word's conventional meaning and guides readers to read out additional meaning of the certain word. For example,

"Daylay egg" (Egg ad)

Besides the coinage of "daylay", the pronunciation of "daylay" is quite similar to "daily". However, most worth considering in this ad is the semantic deviation. Literally, "daylay" means the egg is laid every day; it therefore indicates the freshness and quality of the egg.

Semantics is related to the essential meanings of expressions. Different types of techniques are employed by copywriters at a semantic level to confirm that the advertisement is catchy, objective as well as effective in the long run. Epigrams, metaphors, clichés, similes, utilization of puns and tropes in variable forms are used in semantic-based deviation.

\section{Syntactic Deviation}

The construction of a variety of grammatical sentences in any particular language is termed as Syntactic Deviation. Syntax in the language of advertising constructed sentences for advertisement purposes is remote from syntactic grammar rules and regulations, violating established linguistic set standards. Despite this fact, the ungrammatical structure of sentences in the language of advertising conveys meanings in clarity. Sentences in advertisements do not adhere to the established structure of syntactic grammar; SVO-subject followed by a verb and an object. For example; in Telenor commercial; Sachi yari sab pe bhari, is not a grammatically correct sentence concerning $\mathrm{S}+\mathrm{V}+\mathrm{O}$ etc.

\section{Conclusion}

Thus it is concluded that there, morphological deviation is a useful and harmful driving force in print media's advertisements as far as facts, figures, and this study is concerned. I can say that top brands always enhance their fame and sale on account of linguistic deviation especially, morphological deviation fabricated in the texture of print media advertisements. Undoubtedly, many other linguistic deviations also exist in advertising products, Morphological deviation affects increasingly so far as brand's prominence and sale is concerned. Moreover, with rare exceptions, deviations of all kinds are always in favor of brands whether national or multinational. Morphological based deviation is an influential tool in this connection. Finally, we cannot discard words obtained from deviations, because, of course, these words are unconventional and against the norms, but of great credibility and acknowledgment in our daily life communication, and good addition in standard vocabulary as well. Deviated morphemes like fone, hi; bebe, fuelink, Ufone, and canolive are fine examples in this regard. Certainly, linguistic deviations exist in advertisements of print media; among them, morphological deviation is broadly utilized as compared to blending and orthographic modification. This deviation 
and product's sale are interdependent-closely associated to attract the customers and enhance the sale of the product.

\section{References}

J.Stanton, W. (1984). Fundamentals of Marketing. McGraw-Hill.

Akhbar-e-Jahan, P. (2017, September 11-17). Akhbar-e-Jahan. Weekly Magazine Akhbar-e-Jahan, pp. 4,12 .

Akhbar-e-Jahan. (2017, April Sunday). Akhbar-e-Jahan Pakistan. Weekly, p. 19.

Akhbar-e-Jahan. (2017, January to December weekly). Akhbar-e-Jahan, Pakistan. Weekly Akhbar-eJahan Magazine, p. All.

Akhbar-e-Jahan. (2017, September 11-17). Akhbar-e-Jahan, Pakistan. Weekly Magazine Akhbar-eJahan, p. 4.

Akhbar-e-Jahan. (2017, September,November 11-17,20-26). Akhbar-e-Jahan, Pakistan. Weekly Magazine, pp. 12,65.

Akhbar-e-Jahan. (2017, September 11-17). Akhbar-e-Jahan, Pakistan. Weekly Magazine, p. 9

Antrim. (1973). Publication.

C.A.Moser, G. (2017). Survey Methods in Social Investigation. Routledge.

C.E Potter, T., \& Saffran, J. (2017). Cognitive Science.

Cook, G. (1992). The Discourse of Advertising.

Cook, G. (1992). The Discourse of Advertising. UK, London: Routledge London.

Dawn, P. (2017, January to December Daily). Daily Dawn. Daily Dawn, Pakistan. Rawalpindi, Islamabad, Punjab, Pakistan: Dawn.

Dawn. (2017, March,October 12,29). Dawn News, Pakistan. Daily Dawn Newspaper, pp. 7,3.

Dawn, M. A.-E. (2017, January 5). Dawn News. Daily Dawn News, p. 6.

Dictionary, O. (2001, March 12). Oxford Advanced Learner's Dictionary. Oxford Dictionary. London, England, England: Oxford University Printing Press.

Donnell, T. (1980). Language and Advertising.

Family Magazine, P. (2017, January to December Weekly). Family Magazine, Pakistan. Weekly Family Magazine, p. All.

G.N.Grice. (1975). Logic and Conversation. New York: New York Academic Press.

Grice, P. (1975). Cooperative Principle of Communication.

Grice, P. (1975). Inferential Model for Interpretation and Understanding of contents of Language of Advertisements.

Internet-Wikipedia. (2017, January to December). Internet Wikipedia. Daily.

JW, B., \& J.V, K. (2016). Research in Education. India: Pearson.

L.Bovee, c., \& William F.Arens, D. (1992). Contemporary Advertising.

Lakoff, J. (1980). Publication-Language of advertising.

Leech, G. (1969). A Linguistic Guide To English Poetry.

Magazine, F. (2017, April, May 30,21). Family Magazine, Pakistan. Weekly Magazine, pp. 23,03.

News, T. (2017, November 3). The News, Pakistan. Daily News, Pakistan, p. 2.

News, T. (2017, May, December 25,01). The News, Pakistan. Daily Newspaper, pp. 11,05.

News, T. (2017, November 03,12). The News, Pakistan. Daily Newspaper, pp. 16,02.

News, T. (2017, November, December 14,01). The News, Pakistan. Daily Newspaper, pp. 13,05.

News, T. (2017, November 12,14). The News.Pakistan. Daily News, p. 7.9.

News, T. (2017, January 5). The News. daily, p. 7.

P.Ting, Y. P. (2017). The Journal of Maternal-Fetal \& Neonatal Medicine. The Journal of MaternalFetal \& Neonatal Medicine.

Shakesprare, W. (2017, July 27). Wikipedia. Retrieved July 27, 2017, from Wikipedia: https://en.wikipedia.org/wiki/All_the_world\%27s_a_stage

Sperber, W. (1995). Relevance Theory of Language.

Sperber, W. (1995). Relevance-Communication and Cognition. London.

The News, P. (2017, May 25). The News. Daily Publication-The News Pakistan, p. 7.

The News, P. (2017, January to December Daily). The News Pakistan. The News. Islamabad, Rawalpindi, Punjab, Pakistan: The News, Pakistan.

Trouchstone, K., \& Shamdasani, A. (2017). The Linguistic Service Escape. Journal of Business Research, 147-157. 
Weijter, B., \& Baumga. (2016-2017). Methodological issues in Cross-Linguistic. Multilingual Advertising Research, 115-128.

William. (1980). Publication.

Chi, R., \& Hao, Y. (2013). Language deviation in English advertising. Studies in literature and language, 7(2), 85-89.

Leech, G. (1966). English in Advertising. London: Randolph Quirk, London.

Grijermo, A. (1956). Seduction of Words. Moscow: Burgos, Russia.

Grice, P. (1975). Cooperative Principle of Communication. London: Oxford Printing Press.

Shklovsky, V. (1917). Art as device-Concept of Defamiliarization. Moscow Russia. 